\title{
Manufacturing of Ultra-light Ceramsite from Slate Wastes in Shangri-la, China
}

\author{
Zhen $\mathrm{Li}^{*}$, Haodong Zhang**, Pengshan Zhao*, Xiaoyun He**, and Xiaowei Duan*** \\ *Faculty of Environmental Science and Engineering, Kunming University of Science and Technology, Kunming 650500, China \\ **Yuntou Sci. \& Tech. Ecological Co., Ltd. of Yunnan, Kunming 650011, China \\ ***Yunnan Jingtai Science and Technology Co., Ltd., Kunming 650033, China
}

(Received October 6, 2017; Revised November 15, 2017; Accepted November 20, 2017)

\begin{abstract}
The physical and chemical analyses of mineral waste such as moisture content, water absorption, freezing-thawing resisting sexual, chemical composition and crystal structure were investigated. In the technological process of crushing, screening, molding, drying, preheating, sintering and cooling, many parameters were changed to eliminate the influence of freeze thaw stability and the ball billets were processed into slate ceramsites eventually. Adopting orthogonal experiment and range analysis, the optimal technology parameters were confirmed as preheating temperature of $300^{\circ} \mathrm{C}$ for 25 minutes and sintering temperature of $1230^{\circ} \mathrm{C}$ for 20 minutes. Slate wastes in Shangri-la could foam and expand without any additive. The ultra-light ceramsite could be directly used as building aggregate, since the analysis results of its leaching toxicity were eligible. Besides, effects of sintering temperature on physical property and crystal phase were also explored in this study.
\end{abstract}

Key words : Porous ceramics, Mullite, Thermal expansion, Ultra-light ceramsite, Freeze thaw stability

\section{Introduction}

F or the sake of tourism landscape recovery and ensuring the Tibetans' living safety, the roof reconstruction project obtained a central budget authorization approved by Yunnan Development and Reform Commission, in which color steel tile roof would be replaced by slate tiles. Toward the end of 2015, Stone Industrial Development and Investment Co., Ltd. of Diqing Development and Investment Group delivered the project while still leaving abundant slate wastes in Shangri-la. Filling up the pit with slate wastes or used for road headstone aren't the most cost-effective ways, the enterprise thus entrusted us with research on resource utilization.

Because of its multi-functional characteristics of low density, high porosity, high cylindrical compress strength, good heat-insulating performance-corrosion resistance and good freezing resistance, ${ }^{1,2)}$ ceramsite has been widely used in architecture, ${ }^{3,4)}$ environmental protection, ${ }^{5)}$ metallurgical, ${ }^{6}$ chemical, ${ }^{7}$ agriculture, ${ }^{8)}$ traffic $^{9)}$ and other domains. Slate ceramsites with excellent performances are thus expected to be manufactured primarily, since the slate powders itself are far better than that of sludge, coal gangue, municipal solid waste, etc. Whereas Shangri-la owns unique climate and geographical conditions, the moisture content and freezing thawing stability are distinctly different from that

\footnotetext{
${ }^{\dagger}$ Corresponding author : Haodong Zhang

E-mail : haodong_zhang1971@163.com

Tel : +86-130-7879-6327 Fax : +86-871-6535-8938
}

of other diggings and the existing sintered experience show its certain limitations. And eliminated the ill effects of freeze thaw stability through appropriate roasting process, the properties of slate ceramsites are happily proved to be superior to sludge ceramsite, ${ }^{10,11)}$ lytag, ${ }^{12)}$ municipal solid waste ceramsite, ${ }^{13)}$ lime mud ceramsite, ${ }^{14)}$ and clay ceramsite. $^{15)}$

\section{Experimental Procedure}

\subsection{Raw materials}

Confirmed by the Diqing Comprehensive Inspection Center of Quality and Technical Supervision, the average of natural moisture content, initial water absorption and saturated percent sorption are $0.07,0.2$ and $0.23 \%$, respectively. The test results of rock frost resistance are both listed in Table 1, in which, $\mathrm{L}_{\mathrm{f}}$ and $\mathrm{K}_{\mathrm{f}}$ are on behalf of freezing-thawing mass loss rate and coefficient separately; $R_{\mathrm{s}}$ and $R_{\mathrm{f}}$ represent uniaxial compression strength of saturated rock before and after the experiment, while $\overline{\mathrm{R}}_{\mathrm{s}}$ and $\overline{\mathrm{R}}_{\mathrm{f}}$ are the corresponding averages; pretest-posttest saturated qualities are sequentially replaced by $\mathrm{m}_{\mathrm{s}}$ and $\mathrm{m}_{\mathrm{f}} ; \mathrm{P}_{\mathrm{s}}$ and $\mathrm{P}_{\mathrm{f}}$ successively stand for failure loads of saturated samples before and after freezing-thawing; we have $A_{s}$ and $A_{f}$ instead of cross-sectional area perpendicular to the loading direction.

The raw materials were dried in thermostatic drum wind drying oven (WFO-420W, purchased from Tokyo Rikakikai Co., Ltd., Japan) at $80^{\circ} \mathrm{C}$ for about $120 \mathrm{~min}$, and after cooled down to room temperature, they were crushed up into $2 \mathrm{~mm}$ particles by XPC-100X150 jaw crusher supported by the 
Table 1. The Determination of Rock Frost Resistance

\begin{tabular}{|c|c|c|c|c|c|c|c|}
\hline Test items & Sample 1 & Sample 2 & Sample 3 & Sample 4 & Sample 5 & Sample 6 & Average \\
\hline$\overline{\mathrm{L}_{\mathrm{f}}(\%)}$ & 0.11 & 0.06 & 0.07 & 0.08 & 0.06 & 0.07 & 0.075 \\
\hline $\mathrm{R}_{\mathrm{s}}(\mathrm{MPa})$ & 147.6 & 124.5 & 123.3 & 133.8 & 138.4 & 137.9 & - \\
\hline $\mathrm{R}_{\mathrm{f}}(\mathrm{MPa})$ & 138.2 & 113.6 & 115.1 & 123.6 & 130.5 & 127.4 & - \\
\hline $\mathrm{m}_{\mathrm{s}}(\mathrm{g})$ & 356.593 & 356.518 & 337.235 & 352.481 & 343.749 & 365.883 & - \\
\hline $\mathrm{m}_{\mathrm{f}}(\mathrm{g})$ & 356.203 & 356.298 & 337.004 & 352.213 & 343.547 & 365.628 & - \\
\hline$P_{s}(N)$ & 370476 & 313118 & 306401 & 333162 & 345308 & 341303 & - \\
\hline $\mathrm{P}_{\mathrm{f}}(\mathrm{N})$ & 345500 & 286272 & 284873 & 308382 & 326120 & 317863 & - \\
\hline $\mathrm{A}_{\mathrm{s}}\left(\mathrm{mm}^{2}\right)$ & 2510 & 2515 & 2485 & 2490 & 2495 & 2475 & - \\
\hline $\mathrm{A}_{\mathrm{f}}\left(\mathrm{mm}^{2}\right)$ & 2500 & 2520 & 2475 & 2495 & 2499 & 2495 & - \\
\hline $\mathrm{K}_{\mathrm{f}}$ & \multicolumn{6}{|c|}{0.9291} & - \\
\hline$\overline{\mathrm{R}}_{\mathrm{f}}(\mathrm{MPa})$ & \multicolumn{6}{|c|}{124.733} & - \\
\hline$\overline{\mathrm{R}}_{\mathrm{s}}(\mathrm{MPa})$ & \multicolumn{6}{|c|}{134.250} & - \\
\hline
\end{tabular}

National Engineering Research Center-Waste Resource Recovery (NERC-WRR). The further fracturing process of these particles was conducted by double roll crusher (2PG$\varphi 200 \times 125$, provided by the NERC-WRR), and the cutting diameter could reach at $0.841 \mathrm{~mm}$ (i.e. 20 mesh). Employing quick compression sample pulverizer (KER-F100A, provided by the NERC-WRR), the raw materials were finally comminuted into finer powder and passed through the standard sieve (No: 100, $0.147 \mathrm{~mm}$ ). As a rule of thumb, big fineness goes against the sintering and expanding of ceramsites, while small fineness increases the cost without a better effect. Before prilling raw materials, its crystal phase was qualitatively analyzed by X-ray powder diffraction (XRD) method. The peak positions of raw material are integrallty presented in Fig. 1, which illustrates that the sample includes but not limited to quartz, chlorite-serpentine, nimite, muscovite and illite. Based on the above analysis and a few statistical data supplied by the Yuntou Sci. \& Tech. Ecological co., Ltd. of Yunnan, the slate powder was ultimately identified as salic light metasedimentary rock with lamellar texture.

The Rigaku ZSX-primus II X-ray fluorescence spectroscopy (XRF) was adopted for the determination of raw materials, and the chemical compositions are shown in Table 2.

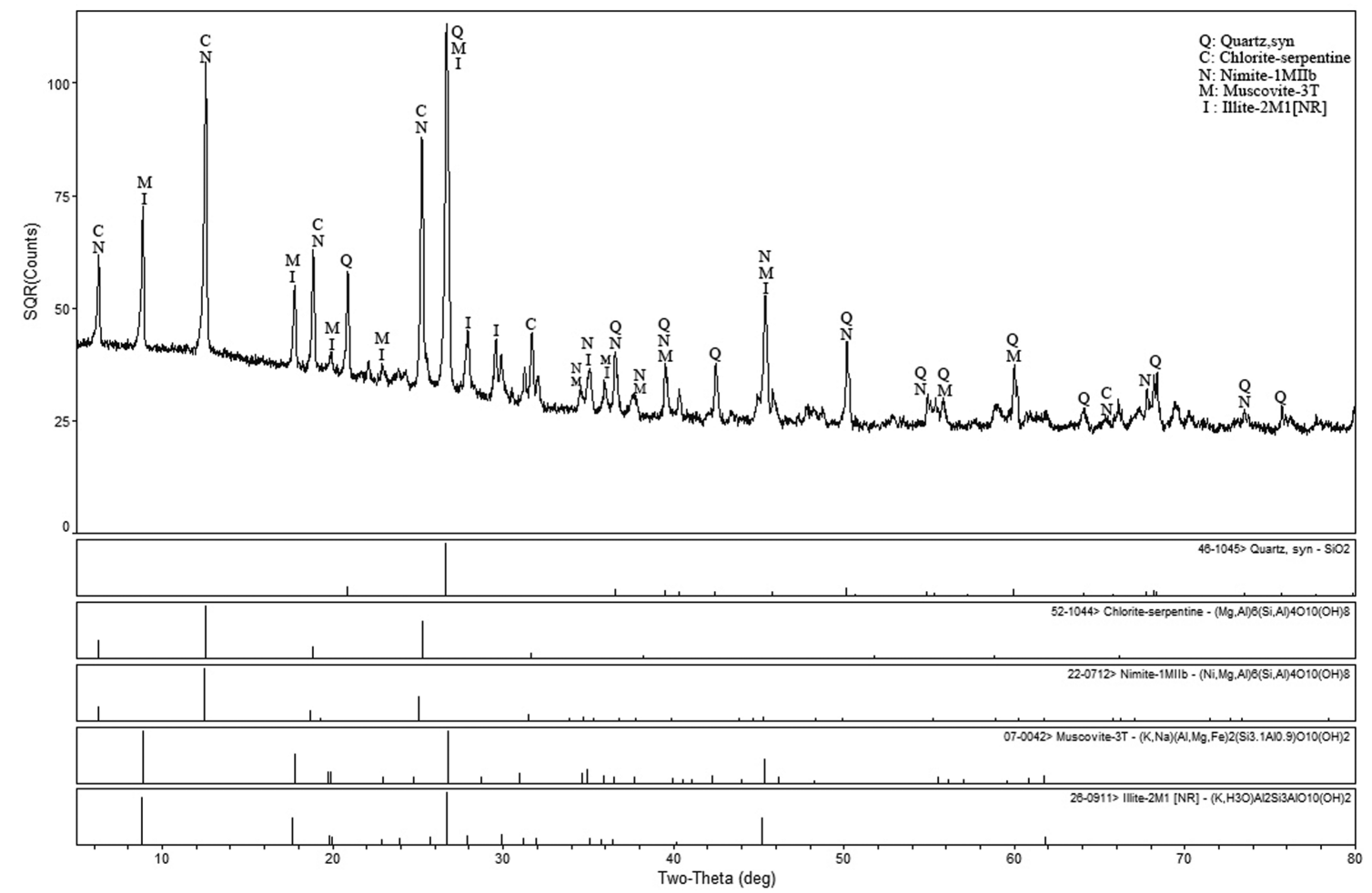

Fig. 1. XRD patterns of raw material. 
Table 2. Chemical Composition of Raw Materials

\begin{tabular}{cccccccc}
\hline Composition & $\mathrm{SiO}_{2}$ & $\mathrm{Al}_{2} \mathrm{O}_{3}$ & $\mathrm{MgO}$ & $\mathrm{Fe}_{2} \mathrm{O}_{3}$ & $\mathrm{~K}_{2} \mathrm{O}+\mathrm{Na}_{2} \mathrm{O}$ & $\mathrm{NiO}$ & $\mathrm{Other}$ \\
\hline Mass fraction (\%) & 61.1 & 18.02 & 6.57 & 5.35 & 4.01 & 1.04 & 3.91 \\
\hline
\end{tabular}

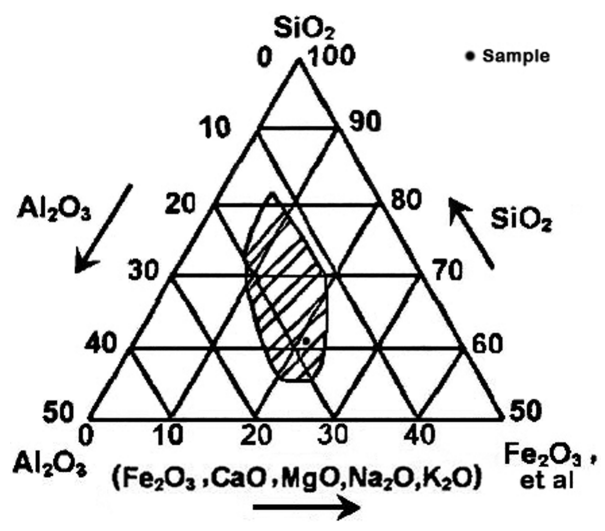

Fig. 2. The phase diagram of Reliy composition.

It can be seen from the three phases diagram of Reliy composition of baking ceramsite (Fig. 2) that this slate composition completely met the requirements of expansive clay $\left(\mathrm{SiO}_{2}: 48-70 \%, \mathrm{Al}_{2} \mathrm{O}_{3}: 8-25 \%\right.$ and Flux: $\left.4.5-31 \%\right)$ as stated by Riley, ${ }^{16)}$ since the sample component located precisely in the shaded area. $\mathrm{SiO}_{2}$ and $\mathrm{Al}_{2} \mathrm{O}_{3}$ act as the skeleton ingredients while other oxides are regarded as fluxing ingredients, whereas $\mathrm{Fe}_{2} \mathrm{O}_{3}$ serves for fluxing ingredient as well as foaming agent. ${ }^{17,18)}$ Besides, the raw materials also contain nickel oxide, which is precisely adhesive agent for ceramic and colorant of glass.

\subsection{Theory and methods}

Various bloating mechanisms associated with Fe compounds have been previously proposed, and the expansion of ceramsite was generally attributed to the decomposition reaction of iron oxides (especially the ferric oxide). ${ }^{19)}$ It appears that the evaporation of free water and interstitial water exert an influence on the process of sintering and expanding, while the losing of crystal water from various minerals could also make certain contribution to the expansion. To describe a series of gas generation processes, some relevant chemical reaction equations were shown as follows: $:^{10,20-21)}$

$$
\begin{aligned}
& 2 \text { Ferric oxide } \stackrel{\text { above } 1100^{\circ} \mathrm{C}}{\longrightarrow} 4 \text { Ferrous oxide }+ \text { oxygen } \uparrow \\
& \text { Ferric oxide }+ \text { Ferrous oxide } \longrightarrow \text { Ferroferric oxide }
\end{aligned}
$$

$$
6 \text { Ferric oxide } \stackrel{\text { above } 1150^{\circ} \mathrm{C}}{\longrightarrow} 4 \text { Ferrous oxide }+ \text { oxygen } \uparrow
$$

2 Ferroferric oxide $\stackrel{\text { above } 1100^{\circ} \mathrm{C}}{\longrightarrow} 6$ Ferrous oxide + oxygen $\uparrow$

The burning expansion mechanism presented in recent years includes both inchoate dynamic balance and upper
Table 3. Factors and Levels of Orthogonal Test

\begin{tabular}{lcccc}
\hline \multirow{2}{*}{ Factors } & \multicolumn{4}{c}{ Levels } \\
\cline { 2 - 5 } & 1 & 2 & 3 & 4 \\
\hline Preheating temperature $/{ }^{\circ} \mathrm{C}(\mathrm{A})$ & 200 & 300 & 400 & 500 \\
Preheating time/min (B) & 15 & 20 & 25 & 30 \\
Sintering temperature $/{ }^{\circ} \mathrm{C}(\mathrm{C})$ & 1100 & 1150 & 1200 & 1230 \\
Sintering time/min (D) & 10 & 15 & 20 & 25 \\
\hline
\end{tabular}

static balance. Because internal pressure was much larger than the liquid surface tension in the early stages, the gases lay in dynamic equilibrium between effusion and suppression of the aqueous phase, and abundant micropores formed inside the ceramisite. However, the liquid phase and surface tension increased sharply with temperature rising in the latter period, and thus the gas evolution suffered a strong inhibition which would lead to the expansion. ${ }^{19}$ ) According to the demand of ceramsite property, the time of inchoate dynamic balance need to be extended, while the time of upper static balance should be cut down.

Manual granulating process was selected to prill the preprocessed raw materials, which required us to keep the surface of ball billet smooth without obvious cracks, and the distribution of particle size was limited to $10-20 \mathrm{~mm}$. Next, the small pelletized raw meals with smooth surface were manufactured into finished products in accordance with the orthogonal scheme. On the basis of multi-ingredient, orthogonal designing method was employed to determine the best manufacturing conditions. The schematic design is based on Table 3 , in which the maximum sintering temperature is set at $1230^{\circ} \mathrm{C}$, since the high temperature of $1250^{\circ} \mathrm{C}$ melts the ball billet in ten minutes. And disadvantages to this method are apparent in the increased complexity, operation effort and financial resources consuming.

According to GB/T 17431.2-2010, ${ }^{22)}$ some physical properties of ceramsite (bulk density, grain density, 1h water absorption, expansion ratio, etc.) should be measured to verify the ceramsite quality. And corresponding values were derived based on specific calculation formulas. ${ }^{23)}$

\section{Results and Discussion}

\subsection{Orthogonal experiment and range analysis}

Having selected the factors and levels, orthogonal experiment was strictly designed and operated in the light of Table 4 . The test results of four performance indexes were also given in this form after calculating. Analysis of means and variances were conducted afterwards to optimize the experiment factors, ${ }^{24)}$ and analysis results emerged from Table 5. It is concluded that the primary and secondary 
Table 4. Design and Result of Orthogonal Experiment

\begin{tabular}{|c|c|c|c|c|c|c|c|c|}
\hline No. & $\mathrm{A}$ & B & $\mathrm{C}$ & $\mathrm{D}$ & $\begin{array}{c}\text { Bulk density } \\
\left(\mathrm{kg} \cdot \mathrm{m}^{-3}\right)\end{array}$ & $\begin{array}{c}\text { Grain density } \\
\left(\mathrm{kg} \cdot \mathrm{m}^{-3}\right)\end{array}$ & $\begin{array}{c}1 \mathrm{~h} \text { Water } \\
\text { absorption (\%) }\end{array}$ & $\begin{array}{c}\text { Expansion ratio } \\
(\%)\end{array}$ \\
\hline 1 & 1 & 1 & 1 & 1 & 887 & 1585 & 7.8 & 7 \\
\hline 2 & 1 & 3 & 4 & 3 & 429 & 743 & 3.42 & 45 \\
\hline 3 & 2 & 1 & 4 & 3 & 418 & 710 & 8.4 & 47 \\
\hline 4 & 2 & 2 & 4 & 3 & 424 & 744 & 9.1 & 49 \\
\hline 5 & 2 & 3 & 1 & 3 & 758 & 1477 & 12.1 & 32 \\
\hline 6 & 2 & 3 & 2 & 3 & 729 & 1431 & 6.3 & 35 \\
\hline 7 & 2 & 3 & 3 & 3 & 676 & 1230 & 5.1 & 41 \\
\hline 8 & 2 & 3 & 4 & 1 & 647 & 1052 & 6.1 & 37 \\
\hline 9 & 2 & 3 & 4 & 2 & 545 & 953 & 6.4 & 42 \\
\hline 10 & 2 & 3 & 4 & 3 & 435 & 762 & 6.5 & 50 \\
\hline 11 & 2 & 3 & 4 & 4 & 419 & 677 & 7.1 & 48 \\
\hline 12 & 2 & 4 & 4 & 3 & 452 & 779.4 & 5.4 & 52 \\
\hline 13 & 3 & 3 & 4 & 3 & 460 & 799 & 4.97 & 53 \\
\hline 14 & 3 & 4 & 3 & 4 & 661 & 1227 & 9.6 & 20 \\
\hline 15 & 4 & 2 & 2 & 2 & 832 & 1473 & 7.3 & 13 \\
\hline 16 & 4 & 3 & 4 & 3 & 445 & 798.7 & 3.55 & 55 \\
\hline
\end{tabular}

order of the influence of the four factors selected in this experiment on the ceramisite properties is as follows: sintering temperature, sintering time, preheating temperature and preheating time, except for some subtle differences lying in the influence on $1 \mathrm{~h}$ water absorption that preheating time abnormally surpassed preheating temperature. The compressive strength, the maximum compressing force that a sinter can withstand before it breaks, ${ }^{25)}$ was the principal factor to determine the most suitable product among various propriety tests for the ceramsite. But to simplify the experiment operation and save the measurement cost, the compressive strength would be tested only when these four performance indexes had already reached the standard. ${ }^{26)}$ The compressive strength among multiple samples in group 10 reached $4.8 \mathrm{MPa}$, which completely fit the ultra-light ceramsite. And the optimal craft group was thus certified as A2B3C4D3 (i.e. No.10 in Table 4). Taking full account of experimental conditions, economical efficiency, made operable and practical, the optimal sintering process was eventually established and exhibited in Fig. 3.

\subsection{Effect of sintering temperature on physical property}

As demonstrated in Fig. 4, the grain density decreased all the time $\left(1477-762 \mathrm{Kg} \cdot \mathrm{m}^{-3}\right)$, when the sintering temperature increased from 1100 to $1230^{\circ} \mathrm{C}$. This tendency could be attributed to coactions of the following two aspects: on the one hand, the exhaust of chemical combined water and decomposition of iron oxide under high temperature reduced the mass of feedstock; on the other hand, part of escaping gases were bound by the surface tension of thermoplastic pellet, which gradually bring about formation of bubbles, inflation of pellets, enlarging of bulk and the final decrease of grain density. Analogously, the bulk density dropped marginally $\left(758-729 \mathrm{Kg} \cdot \mathrm{m}^{-3}\right.$ ) with the temperature going up to $1150^{\circ} \mathrm{C}$, and then fall off obviously.

Figure 5 indicates that the $1 \mathrm{~h}$ water absorption of sintered ceramsite presented a rapid decrease (12.1 - 5.1\%) before sintering temperature reached $1200^{\circ} \mathrm{C}$, and then it went up slightly. The enamel layer on the pellet surface came into being and then the porosity dropped in explanation of water absorption reduction in the early stage. The upper increase might be attributed to the collapse of ceramsite resulting from excessive fusion which might further result in compulsory gas escape, and it's precisely the formation of these surface pores that caused the slight rise of water absorption. In terms of the expansion ratio, it was easy to understand its gradual increase (32 - 50\%) all along the temperature rising.

\subsection{Effect of sintering temperature on crystal phase}

The Fig. 6 vividly reveals the changes on crystal phase of grogs at different sintering temperatures. The characteristic peaks of alkaline silicates (i.e. chlorite, nimite, muscovite and illite) vanished at the sintering temperatures of $1100^{\circ} \mathrm{C}$ while quartz's still exist, which is due to its higher crystallinity and more complete polymorph than other crystal phases. The quartz took on polymorphism forms of aquartz, $\alpha-\mathrm{SiO}_{2}$ or other unclear forms at $1100^{\circ} \mathrm{C}$, while the alkaline silicate turned to glass phase with quartz after sintering. The peak intensity of quartz presented a significant weakening as the temperature rising from $1100^{\circ} \mathrm{C}$ to $1230^{\circ} \mathrm{C}$, since quartz decomposed to amorphous substances during sustained heating process. These amorphous substances gained so high thermal energy that their lattice defect could adjust or eliminate. And thus chemical stability of ceram- 
Table 5. Range Analysis of Four Performance Indexes

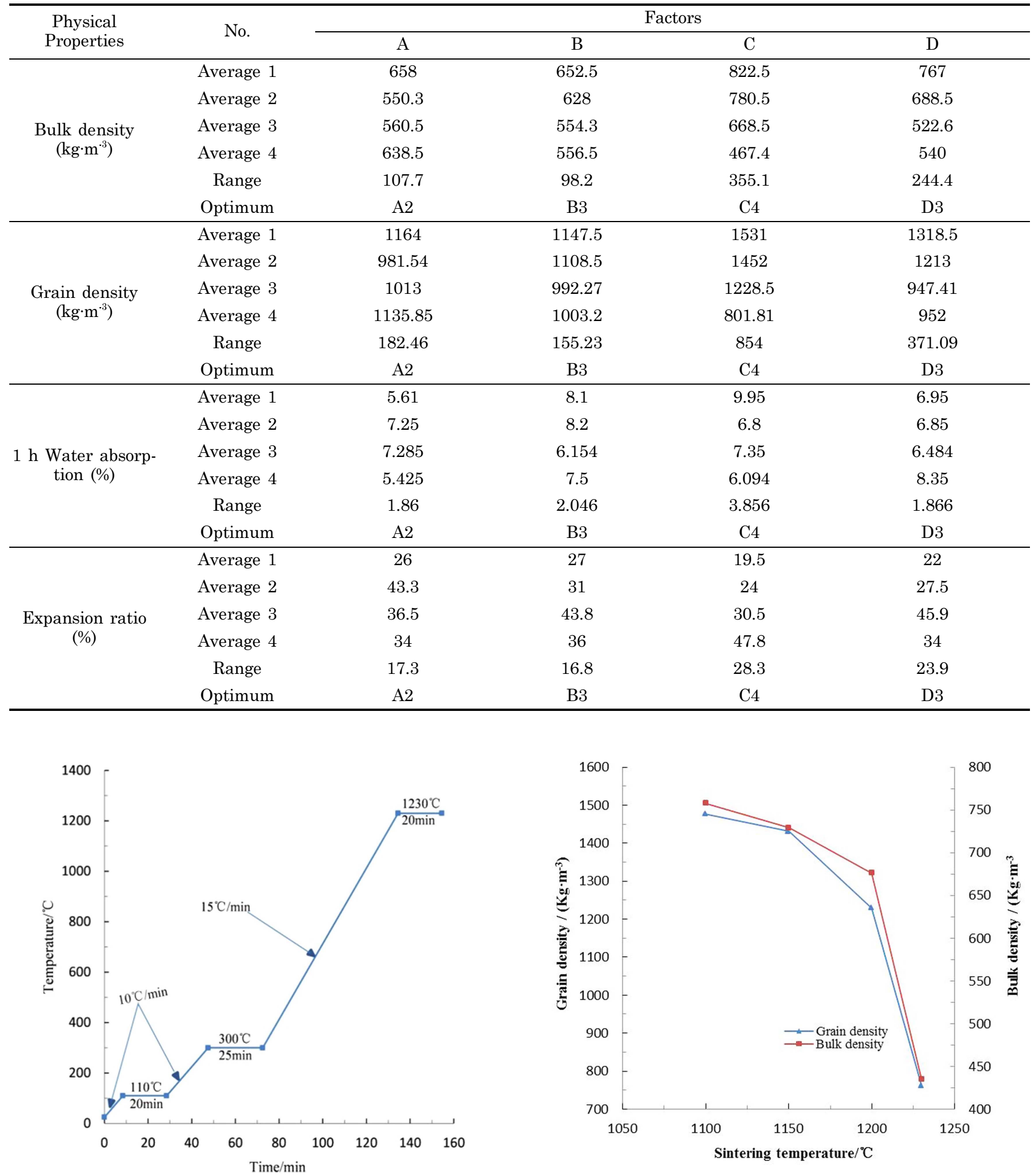

Fig. 3. Temperature rising curve of sintering ceramsites.

site was improved, at the same time that the high-energy state transferred into low-energy state. It is obvious that most of the crystal phases at $1230^{\circ} \mathrm{C}$ exist in the form of
Fig. 4. Variation curves of grain density and bulk density.

oxides, such as Mg-Al-Ga oxide, Fe-Ni-Al oxide and Fe-Al oxide. 


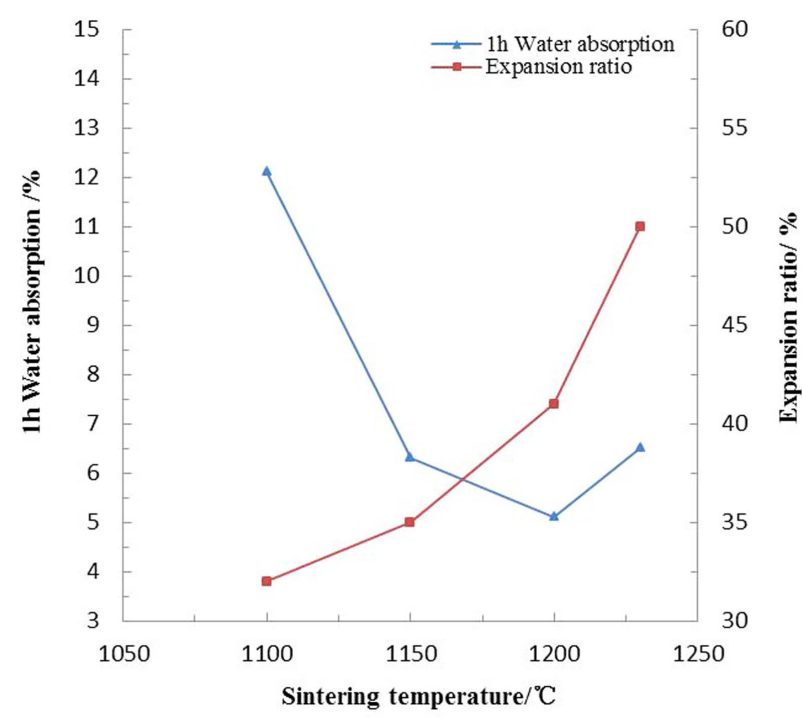

Fig. 5. Variation curves of absorption and expansion ratio.

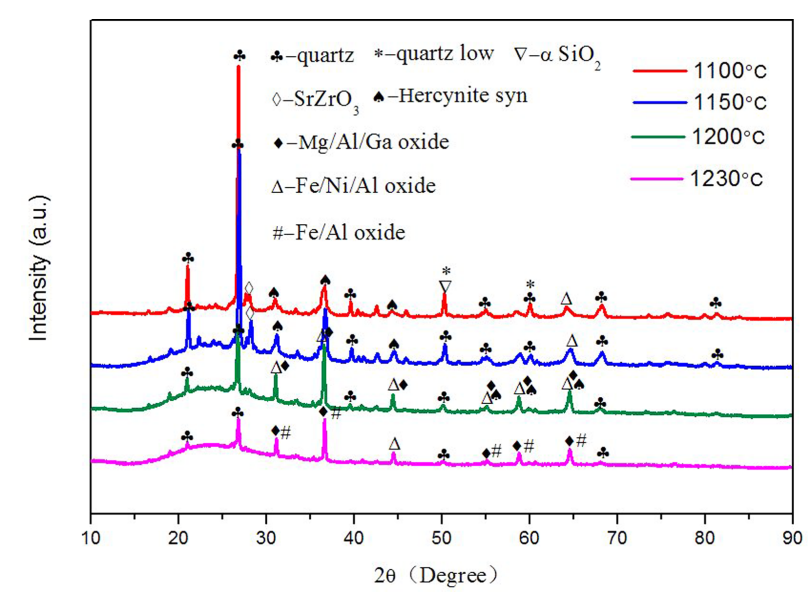

Fig. 6. Effect of sintering temperature on crystal phase.

\subsection{SEM analyses}

Prepared under optimum conditions (preheated at $300^{\circ} \mathrm{C}$ for $25 \mathrm{~min}$ and sintered at $1230^{\circ} \mathrm{C}$ for $20 \mathrm{~min}$ ), the Scanning Electron Microscope (SEM) images were obtained from cross-sections of ultra-light ceramsite. Fig. 7(a) magnified 1000 times reveals the inner honeycomb texture of ultralight ceramsite, which proves that the higher iron content should contribute to burn expansion of ultra-light ceramsite. And the porous structure caused from emission of swelling gases is one of the most critical influences on water absorption. Besides, the ultra-light ceramsites take on its surface topography in Fig. 7(b).

\subsection{Leaching toxicity analyses}

Adopting the method for analyzing the heavy metals from leaching solution of sludge ceramsite, ${ }^{27)}$ the content of nickel in supernatant was measured by using Inductively Coupled Plasma Atomic Emission Spectroscopy (ICP-AES). Results indicated that nickel concentration in the leaching solution
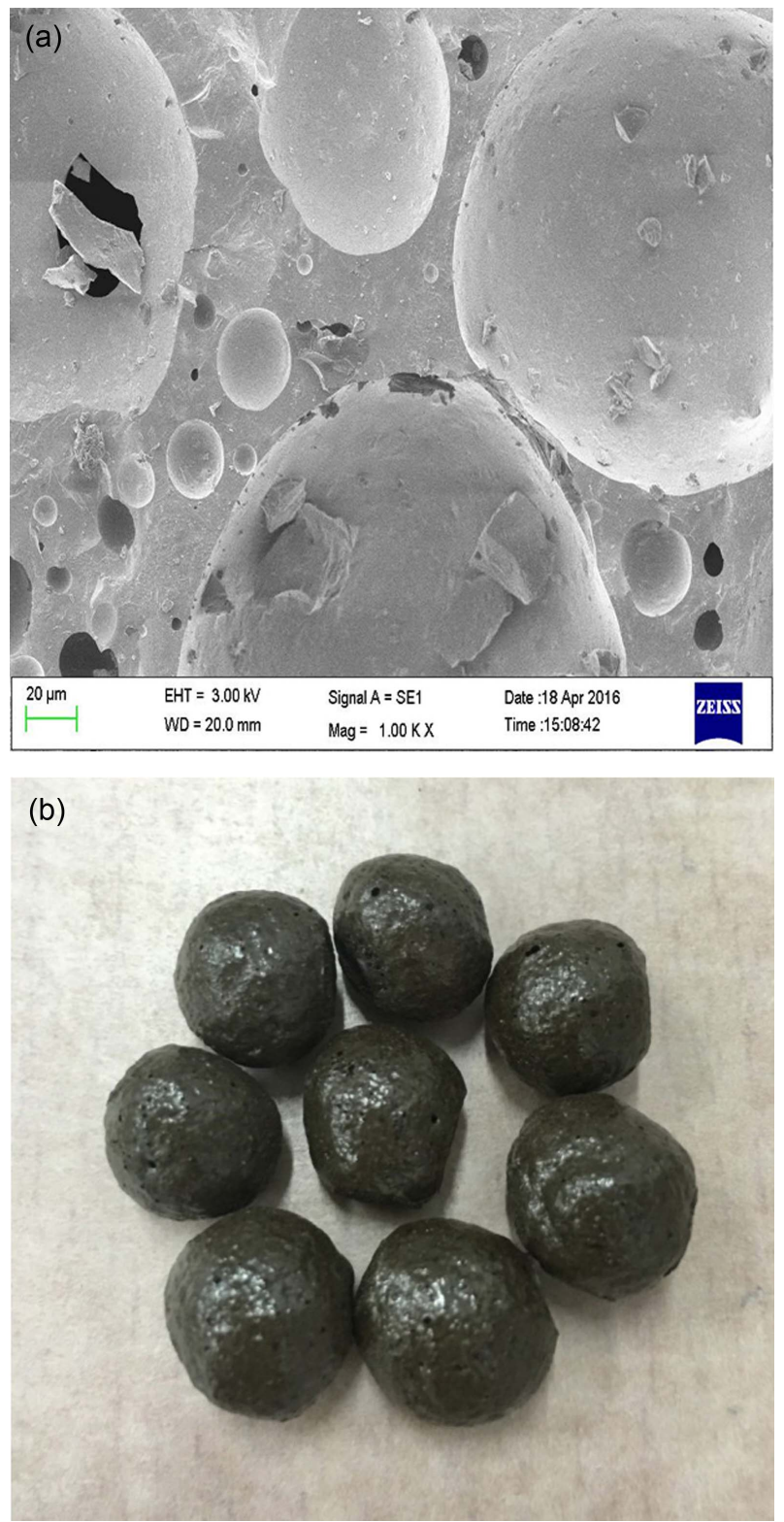

Fig. 7. Images of ultra-light ceramsite (a) SEM and (b) appearance.

is less than $0.1 \mathrm{mg} \cdot \mathrm{L}^{-1}$, which was considerably below the national standard $\left(5 \mathrm{mg} \cdot \mathrm{L}^{-1}\right)$. In conclusion, it is environmentally safe to use ceramsite in civil and construction fields.

\section{Conclusions}

By means of crushing, screening, molding, drying, preheating, sintering and natural cooling to eliminate the impact of freeze thaw stability, slate wastes in Shangri-la ultimately foamed and expanded without any additive. The results of data calculation and graphical analysis indicate that the ceramsites we manufactured own excellent performance and pore texture, which completely meet the require- 
ments of ultra-light ceramsite. The compressive strength reached up to $4.8 \mathrm{MPa}$, meanwhile, the precipitation of heavy metal ion was within limited parameters by ICPAES. In addition, the optimal technology parameters of ultra-light ceramsite (dried at $110^{\circ} \mathrm{C}$ for $20 \mathrm{~min}$, preheated at $300^{\circ} \mathrm{C}$ for $25 \mathrm{~min}$ and sintered at $1230^{\circ} \mathrm{C}$ for $20 \mathrm{~min}$ ) were also determined in this article, and the sintering temperature was listed as the maximum influence by orthogonal experiment and range analysis. The crystal phases at $1230^{\circ} \mathrm{C}$ mainly exist in the form of oxides. On the whole, the slate ceramsites we made completely meet the requirements of building aggregate as well as large-scale manufacture, and the pilot experiment in industrial furnace is underway.

\section{Acknowledgements}

This work was financially supported by the Analysis and Testing Foundation of Kunming University of Science and Technology (Grant No. 2016M20152207018) and the Talent Launch Scientific Research Projects of Kunming University of Science and Technology (Grant No. 14118565).

\section{REFERENCES}

1. J. Malaiskiene, M. Vaiciene, and R. Zurauskiene, "Effectiveness of Technogenic Waste Usage in Products of Building Ceramics and Expanded Clay Concrete," Constr. Build. Mater., 25 [10] 3869-77 (2011).

2. Y. He, X. Zhang, Y. J. Zhang, and Y. Zhou, "Effects of Particle Characteristics of Lightweight Aggregate on Mechanical Properties of Lightweight Aggregate Concrete," Constr. Build. Mater., 72 [15] 270-82 (2014).

3. H. T. He, P. Zhao, Q. Y. Yue, B. Y. Gao, D. T. Yue, and Q. Li, "A Novel Polynary Fatty Acid/Sludge Ceramsite Composite Phase Change Materials and its Applications in Building Energy Conservation," Renewable Energy, 76 4552 (2015).

4. Y. W. Zhou, X. M. Liu, F. Xing, H. Z. Cui, and L. L. Sui, "Axial Compressive Behavior of FRP-confined Lightweight Aggregate Concrete: An Experimental Study and Stress-Strain Relation Model," Constr. Build. Mater., 119 1-15 (2016).

5. T. Bao, T. H. Chen, C. S. Qing, J. J. Xie, and R. L. Frost, "Development and Application of Palygorskite Porous Ceramsite in a Biological Aerated Filter (BAF)," Desalin. Water Treat., 57 [4] 1790-803 (2016).

6. Y. S. Liu, F. Du, L. Yuan, H. Zeng, and S. F. Kong, "Production of Lightweight Ceramisite from Iron Ore Tailings and its Performance Investigation in a Biological Aerated Filter (BAF) Reactor," J. Hazard. Mater., 178 [1-3] 9991006 (2010).

7. S. Z. Yuan, H. Lu, J. Wang, J. T. Zhou, Y. Wang, and G. F. Liu, "Enhanced Bio-decolorization of Azo Dyes by Quinone-functionalized Ceramsites under Saline Conditions," Process Biochem., 47 [2] 312-18 (2012).

8. J. J. Wan, X. M. Liu, P. G. Kerr, C. X. Wu, and Y. H. Wu, "Comparison of the Properties of Periphyton Attached to
Modified Agro-waste Carriers," Environ. Sci. Pollut. Res. Int., 23 [4] 3718-26 (2016).

9. X. Xie, D. Wang, D. Liu, X. Zhang, and M. Oeser, "Investigation of Synthetic, Self-sharpening Aggregates to Develop Skid-resistant Asphalt Road Surfaces," Wear, 348 52-60 (2016).

10. D. T. Yue, Q. Y. Yue, B. Y. Gao, H. T. He, H. Yu, S. L. Sun, Q. Li, Y. Wang, and Y. Zhao, "Preparation and Bloating Mechanism of Porous Ultra-Lightweight Ceramsite by Dehydrated Sewage Sludge and Yellow River Sediments," J. Wuhan Univ. Technol., 29 [6] 1129-35 (2014).

11. I. Merino, L. F. Arevalo, and F. Romero, "Preparation and Characterization of Ceramic Products by Thermal Treatment of Sewage Sludge Ashes Mixed with Different Additives," Waste Manage., 27 [12] 1829-44 (2007).

12. L. H. Li, C. W. Hu, X. L. Dai, W. J. Jin, C. Hu, and F. Ma, "The Performance of a Biological Aerated Filter Loaded with a Novel Non-Sintered Fly-Ash Ceramsite as Pretreatment for Dual Membrane Processes," Environ. Technol., 36 [16] 2024-34 (2015).

13. C. Wang and F. S. Zhang, "Zeolite Loaded Ceramsite Developed from Construction and Demolition Waste," Mater. Lett., 93 380-82 (2013).

14. J. Qin, C. M. Yang, C. Cui, J. T. Huang, A. Hussain, and H. L. $\mathrm{Ma}$, " $\mathrm{Ca}^{2+}$ and $\mathrm{OH}^{-}$Release of Ceramsites Containing Anorthite and Gehlenite Prepared from Waste Lime Mud," J. Environ. Sci., 47 91-9 (2016).

15. X. L. Guo, Y. D. Yao, G. F. Yin, Y. Q. Kang, Y. Luo, and L. Zhuo, "Preparation of Decolorizing Ceramsites for Printing and Dyeing Wastewater with Acid and Base Treated Clay," Appl. Clay Sci., 40 [1-4] 20-6 (2008).

16. C. M. Riley, "Relation of Chemical Properties to the Bloating of Clays," J. Am. Ceram. Soc., 34 [4] 121-28 (1951).

17. I. J. Chiou, K. S. Wang, C. H. Chen, and Y. T. Lin, "Lightweight Aggregate Made from Sewage Sludge and Incinerated Ash," Waste Manage., 26 [12] 1453-61 (2006).

18. H. J. Chen, S. Y. Wang, and C. W. Tang, "Reuse of Incineration Fly Ashes and Reaction Ashes for Manufacturing Lightweight Aggregate," Constr. Build. Mater., 24 [1] 4655 (2010).

19. Y. L. Wei, J. C. Yang, Y. Y. Lin, S. Y. Chuang, and H. P. Wang, "Recycling of Harbor Sediment as Lightweight Aggregate," Mar. Pollut. Bull., 57 [6-12] 867-72 (2008).

20. X. R. Wang, Y. Y. Jin, Z. Y. Wang, R. B. Mahar, and Y. F. Nie, "A Research on Sintering Characteristics and Mechanisms of Dried Sewage Sludge," J. Hazard. Mater., 160 [23] 489-94 (2008).

21. I. Merino, L. F. Arevalo, and F. Romero, "Characterization and Possible Uses of Ashes from Wastewater Treatment Plants," Waste Manage., 25 [10] 1046-54 (2005).

22. "Lightweight Aggregates and its Test Methods-Part2: Test Methods for Lightweight Aggregates," PRC National Standard NO. GB/T17431.2 (2010).

23. Y. F. Qi, Q. Y. Yue, S. X. Han, Y. Min, B. Y. Gao, H. Yu, and T. Shao, "Preparation and Mechanism of Ultra-lightweight Ceramics Produced from Sewage Sludge," J. Hazard. Mater., 176 [1-3] 76-84 (2010).

24. J. Qin, C. Cui, X. Y. Cui, A. Hussain, and C. M. Yang, "Preparation and Characterization of Ceramsite from 
Lime Mud and Coal Fly Ash," Constr. Build. Mater., 95 10-7 (2015).

25. G. R. Xu, J. Z. Zou, and G. B. Li, "Ceramsite Obtained from Water and Wastewater Sludge and its Characteristics Affected by $\left(\mathrm{Fe}_{2} \mathrm{O}_{3}+\mathrm{CaO}+\mathrm{MgO}\right) /\left(\mathrm{SiO}_{2}+\mathrm{Al}_{2} \mathrm{O}_{3}\right)$," Water Res., 43 [11] 2885-93 (2009).
26. "Lightweight Aggregates and its Test Methods-Part1: Lightweight Aggregates," PRC National Standard NO. GB/T17431.21 (2010).

27. G. R. Xu, J. Z. Zou, and G. B. Li, "Stabilization of Heavy Metals in Sludge Ceramsite," Water Res., 44 [9] 2930-38 (2010). 